\title{
ALFREDO LÓPEZ AUSTIN Y LA GRAN RENOVACIÓN DE LOS ESTUDIOS SOBRE EL MÉXICO INDÍGENA
}

\author{
Pablo Escalante Gonzalbo \\ Universidad Nacional Autónoma de México
}

\begin{abstract}
Tace unos meses murió Alfredo López Austin. La cantidad 1 de gente que expresó su emoción por el suceso es bastante elocuente: era un hombre admirado y querido por muchos. Mi propósito en estas notas es sólo el de recordar públicamente, entre historiadores, la trayectoria y el mérito de su contribución científica.
\end{abstract}

\section{DEL NORTE AL SUR, DEL ARTESANO AL CIENTÍFICO}

Alfredo López Austin llevaba el Norte en el corazón, y lo evocaba como un tiempo de libertad. Recordaba con emoción el efecto producido por la lluvia recién caída en el desierto, cuando una delgada capa de vegetación hacía reverdecer la arena. Conoció el mundo del ganado, practicó suertes de charrería, sabía operar a una vaca para extraerle del estómago la pelota de pelo que se les forma por lamerse. En su juventud, en Juárez, se interesó por la poesía y por el dibujo: una curiosidad que nunca se apagó en él, pues le gustaba elaborar las ilustraciones para sus libros, y participó en el diseño de algunas portadas propias y ajenas. En un gesto de gratitud, esculpió la efigie de su maestro, 
Ángel María Garibay, en la punta de un gis, y se la obsequió en alguna de las citas que tuvieron durante los más de dos años en que recibió de él clases particulares de lengua náhuatl. Cuando escribía poesía en su juventud usaba el seudónimo de Melecio Cíbolo, es decir, "el búfalo". Y la última ilustración de portada en su página de Facebook es justamente una danza de los indios de las llanuras con cabezas de búfalo.

Durante sus estudios universitarios, López Austin fue atraído por el mundo académico de la ciudad de México. Después de cursar un año en la Universidad de Nuevo León (1954-1955), completó su carrera de Derecho en la UnAm (1956-1959), institución a la que permanecería ligado por el resto de su vida. El mismo año en que ingresó a la Facultad de Derecho empezó a estudiar la lengua náhuatl con Ignacio Dávila Garibi y se incorporó al Seminario de Cultura Náhuatl de Miguel León Portilla. La atracción por la historia y la lengua indígenas debió ser muy fuerte, pues su tesis fue un trabajo de historia política de los mexicas dirigido por el propio León Portilla: "La constitución real de México Tenochtitlan". ${ }^{1}$

Tras graduarse, López Austin sólo llegó a trabajar un par de años como abogado en su tierra natal. No sentía ninguna motivación para el litigio, y más bien anhelaba volver al medio académico. Lo que sí conservó siempre fue su amor por el Norte. Y, si bien no dedicó ninguna investigación a problemas de las culturas de Aridoamérica, sí sembró ese interés en otros. Siempre recordaba que había que tener presente al México indígena en su totalidad, que Mesoamérica era sólo una parte. Pensaba con frecuencia en los kikapú, etnia a la que, según sus conjeturas, había pertenecido alguno de sus ancestros, y no dejaba de leer sobre arqueología y etnografía de aquella región. A veces pienso que el Norte era como el propio pasado mítico de Alfredo, un

\footnotetext{
${ }^{1}$ Presentada en 1960 y publicada un año después. López Austin, La constitución real.
} 
tiempo algo mágico y maravilloso, tras el cual vino el pecado de la emigración y el tiempo de la creación de esa enorme obra académica.

\section{SOCIEDAD Y POLÍTICA NAHUA}

La primera contribución académica de Alfredo López Austin fue el análisis de las instituciones mexicas que hizo en su tesis de licenciatura, citada hace un momento, y que perfeccionó unos años después en el ensayo "Organización política en el Altiplano Central de México durante el Posclásico". ${ }^{2}$ Con ambos trabajos López Austin trazó un panorama de la estratificación social, la tenencia de la tierra y las estructuras de gobierno, con la terminología original derivada de su estudio de las fuentes en lengua náhuatl. Sobresalen en estos textos las argumentaciones sobre la importancia de los lazos de parentesco en el calpulli y sobre el carácter de las tierras de la nobleza, llamadas pillalli. Para López Austin lo que estaba detrás de esa noción no era una forma de propiedad privada de la tierra, sino una asignación real de parte del usufructo, a la manera de la encomienda.

Una de las propuestas más importantes, desarrollada especialmente en el segundo de estos textos, es la idea de que en Mesoamérica coexistieron un orden de tipo gentilicio y otro de carácter político, que se acoplaban para lograr largos periodos de estabilidad. El cargo de tecubtli habría sido la pieza de enlace de los dos sistemas. El Estado intervenía en el orden gentilicio hasta cierto límite que no podía trasponer. Creo que mucho de la historia de Mesoamérica y algo de la historia colonial se entendería mejor si profundizáramos en esa forma transicional de organización del poder.

${ }^{2}$ López Austin, "Organización política”. 


\section{LA HISTORIA Y EL CÓDICE FLORENTINO}

Tras su regreso a México en 1963, Alfredo colaboró con Miguel León Portilla como subsecretario del Instituto Indigenista Interamericano ${ }^{3}$ y secretario del Instituto de Investigaciones Históricas de la UNAM, donde obtuvo una plaza de investigador auxiliar en 1965. Ese año empezó a estudiar la licenciatura en Historia, tomó aquellas clases particulares de náhuatl con Ángel María Garibay e inició un proceso de auténtica inmersión en el Códice Florentino.

En la misma línea iniciada por Garibay y León Portilla, de publicar traducciones críticas de diferentes secciones de los manuscritos de Sahagún, ${ }^{4}$ López Austin publicó su versión de lo que llamó "juegos rituales aztecas", ${ }^{5}$ y una recopilación de supersticiones y presagios que tituló Augurios abusiones y es uno de los libros más curiosos e interesantes que hay sobre el mundo nahua. ${ }^{6}$ En esta obra asomaba la vida cotidiana de los nahuas como nunca antes se había visto: callejones y baldíos, escenas domésticas, exclamaciones, sustos, hábitos alimenticios, visitas entre parientes. López Austin estaba muy inclinado al análisis de las instituciones y de las estructuras del pensamiento; de tal modo que no reparó especialmente en enfoques como los de la historia cultural y de la vida cotidiana. Sin embargo, dejó un material valiosísimo para seguir esa línea.

Fruto de su primera especialización en los textos sahaguntinos, fue también una serie de artículos dedicados a la magia y

\footnotetext{
${ }^{3}$ No sé hasta qué punto las tareas administrativas le hayan permitido entrar en contacto con los temas e investigadores del resto de América. Pero justo en aquellos años publicó un pequeño estudio sobre los guaraníes. López Austin y CADOGAN, La literatura de los guaranies.

${ }^{4}$ Garibay, Veinte himnos sacros; León Portilla, Ritos, sacerdotes y atavios.

${ }^{5}$ López Austin, Juegos rituales.

${ }^{6}$ López Austin, Angurios y abusiones.
} 
a los magos. ${ }^{7}$ Trabajos muy interesantes y renovadores, en una escena dominada por los sacerdotes solemnísimos de la religión oficial y pública.

Su tesis de licenciatura en Historia se dedicó precisamente a entender cómo se había formado la formidable enciclopedia del mundo nahua que él estaba volcado a estudiar: "Estudio acerca del método de investigación de fray Bernardino de Sahagún. Los cuestionarios". ${ }^{8}$

\section{ENCUENTRO CON QUETZALCÓATL}

Sin abandonar la traducción de la obra de Sahagún, Alfredo se propuso como tema de tesis de maestría el estudio del problema de Quetzalcóatl. Así surgió Hombre dios. Religión y política en el mundo nabua, el primero de sus libros en tener un enorme impacto dentro y fuera de México. Empieza como un trabajo de historia política, incluso de biografía, en busca de Ce Ácatl Topiltzin; considera hechos de gobierno y señoríos específicos, pero a la vez es ya una contribución a la comprensión del pensamiento religioso mesoamericano. La principal afirmación que se desprende de la investigación consiste en que Quetzalcóatl no fue un personaje histórico que se hubiera divinizado, sino un dios que penetraba en el gobernante. El hombre/dios, todos los hombres/dioses de la historia mesoamericana, gobernantes, caudillos, gente de poder, eran hombres habitados por una esencia divina, y actuaban del modo en que lo hacía el dios en el mito.

Al menos en dos trabajos, Alfredo volvería a ocuparse del tema de Quetzalcóatl en relación con los fenómenos del poder

\footnotetext{
7 López Austin, "Los temacpalitotique”; "Términos del nahualatolli”; "Cuarenta clases de magos".

${ }^{8}$ Se presentó en 1969 y se publicaría después, como artículo: López Austin, "The Research Method".

${ }^{9}$ La tesis se presentó en 1972 y apareció como libro el año siguiente, LóPEZ Austin, Hombre dios.
} 
del Posclásico. Me refiero a su artículo "El fundamento mágico-religioso del poder", ${ }^{10}$ y al libro que escribió con su hijo, Leonardo López Luján, muchos años después: Mito y realidad de Zuyuá. ${ }^{11}$

\section{EL CUERPO, LA SALUD Y LA ENFERMEDAD}

A la vez que estudiaba el fenómeno del hombre/dios para su tesis de maestría, López Austin había empezado a traducir del náhuatl y estudiar materiales sobre el cuerpo humano, la salud y la enfermedad, ${ }^{12}$ que formarían parte de su siguiente investigación.

Su tesis de doctorado iba a ser el trabajo más complejo, más extenso; el tratado más formal de cuanto escribió. La comunidad académica la reconoce hoy como una de las obras más importantes sobre el pensamiento indígena; un punto de partida indispensable para estudiar la visión del mundo, no sólo de los nahuas, sino de los pueblos mesoamericanos en general.

López Austin inició sus estudios de doctorado en 1970, cuando era todavía miembro del Instituto de Investigaciones Históricas, y defendió su tesis en 1980. Cuerpo bumano e ideología. Las concepciones de los antiguos nabuas, ${ }^{13}$ (nombre de la tesis doctoral y del libro que se publicó inmediatamente después) representa una bisagra, desde el punto de vista metodológico, entre el estudio de los documentos nahuas del siglo xvI y la proyección de las hipótesis y los modelos en el ámbito de la etnografía.

Durante el proceso del doctorado, López Austin publicó algunos avances parciales de su investigación. Fue muy importante su artículo sobre las partes del cuerpo humano en

\footnotetext{
10 López Austin, "El fundamento mágico”.

11 López Austin y López Luján, Mito y realidad.

12 López Austin, "De las enfermedades"; “Conjuros médicos”.

13 López Austin, Cuerpo bumano.
} 
lengua náhuatl: ${ }^{14}$ un análisis filológico de los textos del corpus de Sahagún, que seguía estando en la base de su metodología. Precisamente de ese enfoque surgió uno de los resultados más concretos e importantes de aquella obra: la identificación de las principales entidades anímicas humanas (tonalli, teyolía ibíyotl) y la relación de cada una de ellas con diferentes conductas, destinos y aspectos de la salud. También publicó durante el proceso su libro Textos de medicina nábuatl,${ }^{15}$ muy usado por los investigadores de la etno-medicina.

\section{EL GIRO}

Alfredo López Austin había pasado más de diez años en el Instituto de Investigaciones Históricas como investigador, como editor de Estudios de Cultura Nábuatl ${ }^{16}$ y como secretario del instituto, cuando decidió cambiar su adscripción al Instituto de Investigaciones Antropológicas. El paso de Alfredo a Antropológicas en 1976 significó un cambio importante para él y para sus colegas, pero también para la metodología y el alcance de su investigación. El cambio de comunidad académica significó una posibilidad de re-enfocar el trabajo con nuevos recursos y métodos. La circunstancia de su cambio de adscripción, cuatro años antes de la conclusión de Cuerpo bumano..., parece estar relacionada con la importancia que tomaron en la obra los estudios de varios antropólogos.

Uno de esos antropólogos a quienes López Austin conoció y aprendió a estimar en su nuevo instituto fue Alfonso Villa Rojas. Recuerdo una ocasión en la que conversábamos Alfredo y yo a la entrada del Instituto y se nos acercó Villa Rojas. Saludó,

\footnotetext{
${ }^{14}$ López Austin, “Textos acerca de las partes”.

${ }^{15}$ López Austin, Textos de medicina.

${ }^{16}$ Había sido editor de la revista en compañía de León Portilla y Garibay, entre el volumen VI y el IX; y lo fue en mancuerna con Víctor Castillo entre el X y el XII.
} 
conversó algún asunto que tenía pendiente con Alfredo, y se despidió. Antes de reanudar nuestra conversación, Alfredo me dijo con una expresión de gran satisfacción "somos enanos en hombros de gigantes”. Le escuché expresiones de admiración similares sobre Kirchhoff, sobre Jiménez Moreno, pero estaba especialmente orgulloso de sus nuevos compañeros antropólogos, como sé que lo estuvo de Víctor Castillo y de Josefina García Quintana en Históricas.

Si bien el punto de partida de la investigación había estado en el análisis filológico, las estrategias comparativas con los estudios etnográficos fortalecieron discusiones importantes, como la que se refiere a la "doctrina” de lo frío y lo caliente en la cosmovisión mesoamericana.

\section{LA LIBERTAD Y EL RIGOR}

La conclusión del doctorado, el fin de las responsabilidades académico-administrativas que durante tanto tiempo había cargado a sus espaldas, y el pertenecer a una nueva comunidad, podrían ser factores que expliquen la libertad de planteamiento de los libros de investigación que Alfredo realizó después.

Yo diría que estaba francamente alegre al concluir el primer borrador de Los mitos del tlacuache. ${ }^{17}$ Fue una obra que le permitió profundizar en aspectos de la cosmovisión que venía meditando, pero entrando ahora por el camino del análisis de los mitos. ¿Era esta ilusión por el estudio de los relatos míticos un reflejo de su antigua sensibilidad artística y del gusto que de joven tuvo por la literatura?

Esa libertad, como no podía ser de otra manera en el caso de Alfredo, venía acompañada de un gran rigor. Él era consciente de la ligereza con la que se usaba lo que, a veces, nombramos “analogía etnográfica” y trató de evitar un tratamiento

17 López Austin, Los mitos. 
oportunista de la información. Más bien avanzó en la construcción de un modelo sobre la tradición religiosa mesoamericana y el lugar que en ella tenían las creencias míticas. Entre las muchas contribuciones de Los mitos del tlacuache, hay una que me parece importante recuperar. Una de las conclusiones posibles de aquel trabajo es que los dioses personales de las religiones estatales encarnaban personajes míticos que habían existido, con funciones similares, mucho antes de las sociedades estatales, y parecen haber sobrevivido al colapso de los Estados. Más de una vez me he preguntado si, en ese sustrato mítico de larga duración, un personaje tan importante como Quetzalcóatl no podría haber transmutado en una criatura más cercana a la comunidad campesina, como el tlacuache: ladrones visitantes del inframundo.

\section{MÁS PARA EL MÉTODO}

Si uno de los trabajos de López Austin está dedicado al método, ése es Tamoanchan y Tlalocan. ${ }^{18} \mathrm{La}$ comparación sistemática y controlada de los repertorios míticos de los tzotziles, los huicholes y los pueblos de la Sierra Norte de Puebla se vuelve un ejercicio de gran utilidad para revisar el enfoque que Alfredo había desarrollado, y que le llevó a afirmar la unidad de la tradición religiosa mesoamericana subyacente a la diversidad étnica. Puso a prueba su método con una propuesta para reconocer y definir Tamoanchan y Tlalocan, dos ámbitos sobrenaturales, nublados, interiores, ligados a las concepciones profundas sobre la manera en que se renueva, se disipa y se recicla la materia sagrada o divina que anima al mundo y forma a los hombres.

López Austin no aspiraba solamente a resolver problemas concretos, como el significado de cierto mito o el sentido de alguna imagen, sino a dejar herramientas metodológicas para el

${ }_{18}$ López Austin, Tamoanchan y Tlalocan. 
análisis de muy diversos asuntos. Y, de hecho, la mejor manera de honrar su legado sería poner a discusión los modelos, conceptos y procedimientos que él desarrolló, y experimentar con ellos.

\section{LA ICONOGRAFÍA}

Conforme avanzaba en el estudio del pensamiento religioso mesoamericano, López Austin valoró la utilidad que sus resultados tenían para la comprensión de la iconografía, e hizo algunos ejercicios sobre esculturas mexicas, como el llamado "Monolito verde" y el "Dios enmascarado del fuego". ${ }^{19} \mathrm{El}$ análisis de las imágenes lo llevó a entender un fenómeno que, de alguna manera, estaba previsto en el modelo de explicación que había ido construyendo: me refiero a lo que llamó “capacidad de fusión y fisión" de los dioses; ${ }^{20}$ la forma en que se dividían o juntaban la sustancias sagradas, coincidiendo a veces dos, distintas, para habitar un espacio como el de la imagen sagrada o ixiptla.

En colaboración con Leonardo López Luján y Saburo Sugiyama abordó la iconografía de un edificio completo, el Templo de Quetzalcóatl en Teotihuacán ${ }^{21}$ y, una vez más, ese análisis modificó la explicación que se había dado durante años a esta construcción.

El último libro de investigación publicado por Alfredo, nuevamente en colaboración con su hijo, estuvo dedicado a explicar el Templo Mayor de Tenochtitlan.22 Están allí presentes, ya depurados, exactos, los procedimientos de investigación que había seguido por muchos años: persisten el análisis filológico de los relatos míticos y el estudio comparado de las concepciones de varios grupos, sobre el origen del maíz, el papel de la montaña,

19 López Austin, “Iconografía mexica”; "El dios enmascarado”.

20 López Austin, "Nota sobre la fusión”.

21 López Austin, López Luján y Sugiyama, “The Temple”.

22 López Austin y López Luján, Monte sagrado. 
las nociones de la riqueza agrícola como tesoro del interior de la tierra.

\section{DIVULGACIÓN Y SÍNTESIS}

No tengo espacio para profundizar más, pero quisiera recordar lo importante que fue para López Austin la publicación de trabajos generales que apoyaran la docencia universitaria y que pusieran los avances al alcance del público general. Una obra sencilla, clara y muy bonita, que él concibió como un texto universitario, fue Tarascos y mexicas, ${ }^{23}$ que incluía síntesis históricas, mapas y antologías de fuentes. Otro manual, más general, fue el que redactó con Leonardo, El pasado indígena. ${ }^{24}$ En esta obra aparece, por fin, el norte de México, de manera extensa y prolija, de Chihuahua a Colorado.

Hay que considerar también, por supuesto, síntesis de divulgación sobre la religión indígena, como las que publicó en compañía de Luis Millones, incluyendo recopilaciones de mitos, tanto de Mesoamérica como de los Andes..$^{25}$

\section{DESPEDIDA}

Una valoración tan rápida, apenas hace justicia a la obra de Alfredo López Austin. Hay que estudiarla y discutirla, reeditarla y aprovecharla en la enseñanza. Ningún investigador ha hecho una contribución al estudio de la religión mesoamericana de la magnitud de la que ha hecho Alfredo. Quizá se podría comparar con la de Eduard Seler, salvo que la del autor de Los mitos del tlacuache es metodológicamente más sólida.

${ }^{23}$ López Austin, Tarascos y mexicas.

${ }^{24}$ López Austin y López Luján, El pasado indígena.

25 López Austin y Millones, Dioses del norte; Los mitos. 
Este no era el lugar para evocar al maestro generoso, al político combativo o al hombre de familia. Cada quien quiere y recuerda de un modo distinto al hombre ejemplar que fue Alfredo López Austin.

\section{SIGLAS Y REFERENCIAS}

GAribay K. Ángel María, Veinte himnos sacros de los nabuas, México, Universidad Nacional Autónoma de México, 1958.

León Portilla, Miguel, Ritos, sacerdotes y atavíos de los dioses, México, Universidad Nacional Autónoma de México,1958.

López Austin, Alfredo, La constitución real de México-Tenochtitlan, México, Universidad Nacional Autónoma de México, 1961.

López Austin, Alfredo, "Los temacpalitotique. Profanadores, brujos, ladrones y violadores”, en Estudios de Cultura Nábuatl, vi (1966), pp. 97-117.

López Austin, Alfredo, Juegos rituales aztecas, México, Universidad Nacional Autónoma de México, 1967.

López Austin, Alfredo, “Términos del nahuallatolli”, en Historia Mexicana, XVII: I (65) (jul.-sep. 1967), pp. 1-36.

López Austin, Alfredo, "Cuarenta clases de magos en el mundo azteca”, Estudios de Cultura Nábuatl, viI (1967), pp. 87-118.

López Austin, Alfredo, Augurios y abusiones, México, Universidad Nacional Autónoma de México, 1969.

López Austin, Alfredo, "De las enfermedades del cuerpo humano y de las medicinas contra ellas", en Estudios de Cultura Nábuatl, viII (1969), pp. 51-122.

López Austin, Alfredo, “Conjuros médicos de los nahuas”, en Revista de la Universidad de México, xIv,11 (jul. 1970), pp. 1-16.

López Austin, Alfredo, Textos de medicina nábuatl, México, Secretaría de Educación Pública, 1971 (sep/Setentas, 6). 
López Austin, Alfredo, "Textos acerca de las partes del cuerpo humano y las enfermedades y medicinas en los Primeros Memoriales de Sahagún", en Estudios de Cultura Nábuatl, x (1972), pp. 129-154.

López Austin, Alfredo, Hombre-dios. Religión y política en el mundo nábuatl, México, Universidad Nacional Autónoma de México, 1973.

López Austin, Alfredo, “The Research Method of Fray Bernardino de Sahagún: The Questionnaires”, en Munro Edmonson (ed.), Sixteenth-Century Mexico. The Work of Sahagun, Albuquerque, University of New Mexico Press, 1974.

López Austin, Alfredo, "Organización política en el Altiplano Central de México durante el Posclásico”, en Historia Mexicana, xxiII: 4 (92) (abr.-jun. 1974), pp. 515-550.

López Austin, Alfredo, "El fundamento mágico-religioso del poder", en Estudios de Cultura Nábuatl, XII (1976), pp. 197-240.

López Austin, Alfredo, "Iconografía mexica. El monolito verde del Templo Mayor", en Anales de Antropología, XvI (1979), pp. 133-153.

López Austin, Alfredo, Cuerpo humano e ideología. Las concepciones de los antiguos nahuas, 2 vols., México, Universidad Nacional Autónoma de México, 1980.

López Austin, Alfredo, Tarascos y mexicas, México, Secretaría de Educación Pública, Fondo de Cultura Económica, 1981.

López Austin, Alfredo, "Nota sobre la fusión y la fisión de los dioses en el panteón mexica”, en Anales de Antropología, XX-II (1983), pp. 75-87.

López Austin, Alfredo, "El dios enmascarado del fuego", en Anales de Antropología, xXII (1985), pp. 251-285.

López Austin, Alfredo, Los mitos del tlacuache. Caminos de la mitología mesoamericana, México, Alianza Editorial Mexicana, 1990.

López Austin, Alfredo, Tamoanchan y Tlalocan, México, Fondo de Cultura Económica, 1994.

López Austin, Alfredo y León Cadogan, La literatura de los guaraníes, México, Editorial Joaquín Mortiz,1965. 
López Austin, Alfredo y Leonardo López Luján, El pasado indígena, México, El Colegio de México, Fideicomiso Historia de las Américas, Fondo de Cultura Económica, 1996.

López Austin, Alfredo y Leonardo López LujÁn, Mito y realidad de Zuyuá. Serpiente Emplumada y las transformaciones mesomericanas del Clásico al Posclásico, México, El Colegio de México, Fideicomiso Historia de las Américas, Fondo de Cultura Económica, 1999.

López Austin, Alfredo y Leonardo López Luján, Monte sagrado-Templo Mayor, México, Instituto Nacional de Antropología e Historia, Universidad Nacional Autónoma de México, 2009.

López Austin Alfredo y Luis Millones, Dioses del Norte, dioses del Sur. Religiones y cosmovisión en Mesoamérica y los Andes, México, Era, 2008.

López Austin Alfredo y Luis Millones, Los mitos y sus tiempos. Creencias y narraciones de Mesoamérica y los Andes, México, Ediciones Era, 2015.

López Austin, Alfredo, Leonardo López Luján y Saburo Sugryama, “The Temple of Quetzalcoatl at Teotihuacan: Its Possible Ideological Significance", en Ancient Mesoamerica, 2 (1991), pp. 93-105. 